\title{
Exercise-induced anterior tibial compartment compression syndrome in the elderly
}

\author{
R. C. SWEENEY \\ M.B., Ch.B.
}

\author{
C. J. Chadwick \\ M.B., Ch.B., F.R.C.S.
}

\author{
W. E. BAgnall \\ B.Sc., M.B., Ch.B., M.R.C.P.
}

St James's University Hospital, Beckett Street, Leeds 9

\begin{abstract}
Summary
Exercise-induced anterior tibial compartment compression syndrome occurs predominantly in young males. The authors report a case in a 79-year-old female as a complication of rehabilitation.

\section{Introduction}

A compartmental syndrome is defined as a condition in which elevated pressure in an osteofascial compartment produces dysfunction or necrosis of the enclosed tissues (Matsen, 1975). The anterior tibial compartment (ATC) is surrounded by dense fibrous tissue, bone and interosseous membrane forming a rigid boundary, thus making raised pressure especially likely to be damaging. The ATC contains the extensors of the foot and toes, the deep peroneal nerve and the anterior tibial blood vessels and pressure damage to these structures produces the clinical picture of the ATC compression syndrome. $A$ raised ATC pressure may be due to vascular occlusion, exercise, trauma or other causes (Bradley, 1973). ATC compression following exercise is a syndrome occurring mostly in young males (Bradley, 1973). It has not previously been reported from an elderly female.
\end{abstract}

\section{Case report}

A 79-year-old woman was admitted because of decreasing mobility over several months; for the 8 weeks immediately before admission she had become completely bedfast.

On examination, she was sensible but depressed, and showed generalized wasting. She was in atrial fibrillation and mild congestive cardiac failure, with signs of aortic and mitral regurgitation. Faecal impaction was the only other abnormal physical finding.

She was treated with digoxin, diuretics, a laxative and subsequently antidepressants. Active functional rehabilitation was commenced on the day of admis- sion, involving intensive walking exercises, dressing practice, self-toileting and finally kitchen assessment. At the end of 10 days she was physically well, independent in carrying out the activities of daily living, and discharge was considered.

However, at this time the patient first complained of pain down the right shin associated with slight weakness of dorsiflexion of the foot. There were no other physical signs, and spontaneous resolution took place within a few hours. In the evening of the subsequent 2 days she had a recurrence of these symptoms, again resolving without intervention.

On the fourth day the patient had severe right shin pain. Examination revealed oedema and erythema of the skin covering the ATC and the underlying muscle was tender and swollen. Active dorsiflexion of the foot and toes was weak, and exacerbated the pain, while passive movement (notably plantarflexion and inversion of the foot) caused exquisite pain in the anterior compartment. Skin temperature was unchanged and foot pulses were present. Sensation in the first web space was not tested.

A clinical diagnosis of ATC compression syndrome was made and urgent fasciotomy performed. At operation the muscle showed the characteristic bulging through the divided fascia (French and Price, 1962). Following surgery, the patient made a good functional recovery, with return to full power in the affected muscles. Skin healing was delayed but she was eventually discharged home, mobile and independent.

\section{Comment}

This 79-year-old woman developed the classical, clinical and pathological features of an acute ATC compression syndrome. The premonitory symptoms with spontaneous resolution after rest, the lack of history of trauma, the characteristic findings at operation and the full return to function after fasciotomy lead the authors to suggest that, in the 
absence of any evidence indicating an acute arterial block, this was a true exercise-induced syndrome. Exercise-precipitated ATC compression occurs in males in $96 \%$ of reported cases, with a median age of 25 years (Bradley, 1973). The previously reported cases of ATC compression in elderly subjects have been as a complication in the evolution of a peripheral arterial block (Freedman and Knowles, 1959; Lytton and Blandy, 1960; Totten, 1963; Watson, 1955).

Anterior tibial compartment compression secondary to unaccustomed exercise is a syndrome requiring urgent surgery and includes permanent footdrop and severe muscle necrosis amongst its serious sequelae from which the elderly are not immune.

\section{References}

Bradley, E.L. (1973) The anterior tibial compartment syndrome. Surgery, Gynecology and Obstetrics, 136, 289.

FreEdman, B.J. \& KNOWLES, C.H.R. (1959) Anterior tib syndrome due to arterial embolism and thrombosif. British Medical Journal, 2, 270.

French, E.B. \& Price, W.H. (1962) Anterior tibial pai British Medical Journal, 2, 1290.

LytTon, B. \& BLANDY, J.P. (1960) Anterior tibial syndror after embolectomy. Brinish Journal of Surgery, 48, 346. @

Matsen, F.A. (1975) Compartmental syndromes; a unified concept. Clinical Orthopaedics, 113, 8.

Totten, A.P. (1963) Anterior tibial syndrome due to proximad artery thrombosis. Angiology, 14, 358 .

Watson, D.C. (1955) Anterior tibial syndrome followi通 arterial embolism. British Medical Journal, 1, 1412. 